Abstract AB0402 - Table 1. Cardiorenal continuum features of rheumatoid arthritis patients (\%)

\begin{tabular}{|c|c|c|c|c|c|c|c|c|}
\hline & \multirow[t]{2}{*}{ Features } & \multicolumn{3}{|c|}{ Rituximab group } & \multicolumn{3}{|c|}{ Control group } & \multirow[t]{2}{*}{$P_{\text {R-C }}$} \\
\hline & & 1 year, $n=50$ & 3 years, $n=47$ & 6 years, $n=31$ & 1 year, $n=30$ & 3 years, $n=26$ & 6 years, $n=16$ & \\
\hline \multirow[t]{7}{*}{ Risk factors } & Hypertension & 50.0 & 38.3 & $\begin{array}{c}25.8 \\
p_{6-1}=0.028\end{array}$ & 40.0 & 38.5 & 50.0 & $p_{6}=0.032$ \\
\hline & Dyslipidaemia & 44.0 & 36.2 & 38.7 & 40.0 & 46.2 & 50.0 & $>0.05$ \\
\hline & Pre-diabetes & 52.0 & 36.2 & 41.9 & 33.3 & 34.6 & 56.3 & $>0.05$ \\
\hline & Metabolic syndrome & 12.0 & 6.4 & 3.2 & 10.0 & 7.7 & 12.5 & $>0.05$ \\
\hline & Diabetes mellitus & 4.0 & 0 & 0 & 0 & 0 & 0 & $>0.05$ \\
\hline & Anxiety/depression & 83.2 & 41.5 & 35.3 & 80.0 & 73.1 & 68.8 & $\mathrm{p}_{3}=0.009$ \\
\hline & & & $\mathrm{p}_{3-1}=0.006$ & $\mathrm{p}_{6-1}<0.001$ & & & & $\mathrm{p}_{6}=0.008$ \\
\hline \multirow[t]{7}{*}{ Initial stages } & Atherosclerosis & 32.0 & 21.3 & 12.9 & 40.0 & 34.6 & 37.5 & $\mathrm{p}_{6}=0.02$ \\
\hline & & & & $p_{6-1}=0.048$ & & & & \\
\hline & Left ventricular hypertrophy & 8.0 & 4.3 & 0 & 6.7 & 7.7 & 0 & $>0.05$ \\
\hline & Diastolic dysfunction & 48.0 & 38.3 & 22.6 & 46.7 & 50.0 & 56.3 & $\mathrm{p}_{6}=0.04$ \\
\hline & & & & $p_{6-1}=0.022$ & & & & \\
\hline & Albuminuria & 8.0 & 0 & 0 & 0 & 0 & 6.3 & $>0.05$ \\
\hline & Kidney impairment & 6.0 & 2.1 & 0 & 13.3 & 0 & 0 & $>0.05$ \\
\hline \multirow[t]{2}{*}{ Progression } & Angina & 6.0 & 0 & 0 & 3.3 & 0 & 0 & $>0.05$ \\
\hline & Chronic kidney disease & 16.0 & 8.5 & 9.7 & 13.4 & 0 & 0 & $>0.05$ \\
\hline \multirow[t]{4}{*}{ End stage } & Myocardial infarction/stroke & 0 & 0 & 0 & 0 & 0 & 0 & $>0.05$ \\
\hline & Heart failure & 2.0 & 0 & 0 & 0 & 0 & 0 & $>0.05$ \\
\hline & Acute/chronic renal failure & 0 & 0 & 0 & 0 & 0 & 0 & $>0.05$ \\
\hline & Death & 0 & 0 & 12.9 & 0 & 0 & 0 & $>0.05$ \\
\hline
\end{tabular}

Disclosure of Interest: None declared

DOI: 10.1136/annrheumdis-2017-eular.5704

\section{AB0403 ADHERENCE AND ACCESS TO BIOLOGICAL THERAPY AND TOFACITINIB IN A COHORT OF COLOMBIAN PATIENTS WITH RHEUMATOLOGICAL DISEASES}

J.E. Machado-Alba, M.E. Machado-Duque, S. Granada on behalf of Grupo de Investigación en Farmacoepidemiología y Farmacovigilancia, Universidad Tecnológica de Pereira-Audifarma S.A, Pereira, Colombia. Grupo de Investigación en Farmacoepidemiología y Farmacovigilancia, Universidad Tecnológica de Pereira-Audifarma S.A, Pereira, Colombia

Background: Biological disease-modifying antirheumatic drug (bDMARD) and tofacitinib are highly effective, but with different pharmaceutical forms, adverse reactions and cost that could affect adherence therapy and drug access.

Objectives: To determine patient adherence and administrative access to the treatment with bDMARDs and tofacitnib in patients with rheumatological diseases in Colombia.

Methods: A retrospective cohort study, which included all patients in management with bDMARD and tofactinib initiated between July 1, 2015 and June 30, 2016. A monthly follow-up of the administrative adherence were evaluated by holding or applying the medication, as well as the application of Morisky-Green test in self-administered oral and subcutaneous therapies (non-adherent patient was considered when at least one doses is lost), other variables such as sociodemographic, comorbidities, and co-prescriptions were evaluated. A descriptive analysis, $\chi^{2}$ for comparison and multivariate logistic regression were performed. Results: A total of 1102 patients were evaluated, with a mean age of $52.8 \pm 15.4$ years and a female predominance $(72.8 \%)$. The most frequent comorbidities were hypertension (22.6\%) and dyslipidemia (15.9\%). The most prescribed drugs studied were adalimumab $(31.9 \%)$, etanercept $(22.2 \%)$ and tofacitinib (12.5\%). 52.8\% use conventional DMARDs and $42.2 \%$ use glucocorticoids. Global adherence was $66.3 \%$ as measured by Morisky-Green test. Adherence was better with self-administered subcutaneous drugs every week or longer, compared to daily dosing of oral drug; these data are detailed in table 1. In $42.4 \%$ of the patients, at least one delay per year in the application or dispensation occurred, leading to $36.1 \%$ of patients experiencing dose losses due to difficulties in access. The main reason (23\%) for delays and dose losses is the failures by health-insurance companies to allow timely access to the therapy. In the multivariate analysis treatment with adalimumab or tofacitinib was associated with a greater probability of presenting delays in access after adjustment of variables.

\begin{tabular}{|c|c|c|c|c|c|c|}
\hline Drug & (n) & (\%) & $\begin{array}{l}\text { Drug administration route and } \\
\text { interval }\end{array}$ & $\begin{array}{c}\text { Morisky-Green } \\
\text { test adherence } \\
\text { (\%) }\end{array}$ & $\begin{array}{l}\text { At least one dose } \\
\text { application delay in the } \\
\text { year of follow up (\%) }\end{array}$ & $\begin{array}{l}\text { Missed } \\
\text { dose (\%) }\end{array}$ \\
\hline Adalimumab & 351 & 31.9 & SC-Every two weeks & 74.8 & 62.7 & 51.3 \\
\hline Etanercept & 245 & 22.2 & SC-weekly & 72 & 27.3 & 22.4 \\
\hline Tofacitinib & 138 & 12.5 & $\mathrm{OA}$ - every 12 hours & 48.8 & 52.2 & 52.2 \\
\hline Golimumab & 82 & 7.4 & SC- monthly & 64.7 & 32.9 & 28 \\
\hline Rituximab & 66 & 6.0 & IV - biannual and annual & Not apply & 3.0 & 1.5 \\
\hline Certolizumab & 58 & 5.3 & SC - monthly & 83.3 & 32.8 & 32.8 \\
\hline Infliximab & 40 & 3.6 & IV - monthly and every two months & Not apply & 35.0 & 27.5 \\
\hline Abatacept & 62 & 5.6 & IV y SC- monthly and weekly & 42.9 -(SC route) & 38.7 & 27.4 \\
\hline Tocilizumab & 60 & 5.4 & IV y SC-monthly & $50.0-(\mathrm{SC}$ route) & 36.7 & 33.3 \\
\hline
\end{tabular}

Conclusions: Subcutaneous self-applications of bDMARD have better adherence rates compared to oral drug. However, the limitations in access to treatment decrease the adherence. On the other hand the impact of the adherence could be major in the case of self-administered DMARD when weekly or longer intervals doses are lost, compared with the loss of one daily dose of tofacitinib.
References:

[1] Scott DL, et al. Rheumatoid arthritis. Lancet. 2010;376(9746):1094-108.

[2] Machado-Alba JE, et al. Effectiveness of treatment with biologic- and DMARD in rheumatoid arthritis patients in Colombia. Int J Clin Pract. 2016;70(6):50611.

[3] Jorgensen TS, et al. Effectiveness and drug adherence of biologic monotherapy in routine care of patients with rheumatoid arthritis: a cohort study of patients registered in the Danish biologics registry. Rheumatology. 2015;54(12):215665.

Acknowledgements: To Universidad Tecnológica de Pereira and Audifarma S.A Disclosure of Interest: J. Machado-Alba Grant/research support from: The authors declare that Pfizer Colombia financed the data collection process in medical records. There was no intervention in the stages of processing, analysis or publication of that data. No non-financial conflicts of interest exist for any of the authors., M. Machado-Duque: None declared, S. Granada: None declared DOI: 10.1136/annrheumdis-2017-eular.5263

\section{AB0404 SIMILAR REMISSION RATES AMONG RHEUMATOID ARTHRITIS PATIENTS TREATED WITH ANTI TNF AND NON-ANTI TNF THERAPIES: REAL-LIFE DATA}

J.A. Gómez-Puerta ${ }^{1,2}$, N. Duque ${ }^{1}$, M. Saldarriaga ${ }^{1}$, L.A. González ${ }^{1,2}$, C. Cerón ${ }^{1}$, L. Uribe Botero ${ }^{1}$, O.J. Felipe-Díaz ${ }^{1}$. ${ }^{1}$ Medicarte IPS; ${ }^{2}$ Grupo de Reumatología, Universidad de Antioquia, Medellín, Colombia

Background: Several biological DMARD (bDMARD) therapies have been approved for use in rheumatoid arthritis (RA) and are classified according to their respective therapeutic target: Anti TNF therapies and non-Anti TNF therapies. They are very effective in most of patients but their comparative efficacy in daily clinical is less well known.

Objectives: Our aim was to compare the efficacy of anti-TNF therapies vs non-Anti TNF therapies in a cohort of Colombian RA patients followed in different arthritis clinics under daily clinical practice conditions.

Methods: We conducted a cross-sectional study including with RA patients treated at Medicarte IPS from March 2009 to December 2016. Medicarte is a referral center for the integral medical care and pharmaco-surveillance of patients under biologic therapies in 13 cities in Colombia for inflammatory arthropathies, mainly RA, psoriatic arthritis and spondyloartropathies. Clinical information was obtained from electronic clinical records and medical claims. Only those patients with disease activity scores (DAS-28) at baseline and at the last visit were included. Remission was defined as DAS-28 $<2.6$ on the last visit. Patients treated only with conventional DMARD and/or tofacitinib were excluded.

Results: A total of 1,020 patients with RA were identified. 844 patients $(88 \%$ female) were included in the final analysis, 416 patients with anti TNF and 428 with non-anti TNF therapies (Rituximab 199, Tocilizumab 125 and Abatacept in 104 patients). The mean age was $55.2 \pm 11.8$ years, with a mean disease duration

Table 1. General Characteristics of patients with RA under bDMARD therapy

\begin{tabular}{lcccc}
\hline & $\begin{array}{c}\text { Total } \\
\mathrm{N}=844\end{array}$ & $\begin{array}{c}\text { Anti TNF } \\
\mathrm{N}=416\end{array}$ & $\begin{array}{c}\text { Non-Anti TNF } \\
\mathrm{N}=428\end{array}$ & $\mathrm{p}$ value \\
\hline Gender (female) \% & 88.0 & 88.7 & 87.6 & $\mathrm{NS}$ \\
Age (years, SD) & $55.2 \pm 11.8$ & $55.0 \pm 11.8$ & $55.4 \pm 11.8$ & $\mathrm{NS}$ \\
Disease duration (years, SD) & $15.2 \pm 9.5$ & $15.0 \pm 9.9$ & $15.5 \pm 9.0$ & $\mathrm{NS}$ \\
bDMARD therapy duration (years) & $3.2 \pm 2.5$ & $3.2 \pm 2.5$ & $3.2 \pm 2.4$ & $\mathrm{NS}$ \\
First line bDMARD therapy,\% & 64.0 & 75.2 & 53.2 & $\mathrm{p}<0.001$ \\
Combined therapy, \% & 83.0 & 90.9 & 75.0 & $\mathrm{p}<0.001$ \\
Seropositive (either CCP and/or RF) \% & 80.1 & 82.0 & 78.3 & $\mathrm{NS}$ \\
DAS-28 at baseline $( \pm \mathrm{SD})$ & $4.3 \pm 1.1$ & $4.20 \pm 1.14$ & $4.4 \pm 1.21$ & $\mathrm{NS}$ \\
HAQ at baseline $( \pm \mathrm{SD})$ & $1.13 \pm 0.77$ & $1.09 \pm 0.78$ & $1.16 \pm 0.77$ & $\mathrm{NS}$ \\
\hline
\end{tabular}

